\title{
PRODUTIVIDADE DE GRAMÍNEAS CULTIVADAS EM SISTEMAS ALAGADOS CONSTRUÍDOS NO NORTE DE MINAS GERAIS
}

\author{
Viktor Kayro Souza Santos ${ }^{1}$ \\ Ana Paula Ferreira Colares ${ }^{2}$ \\ Rodrigo Nogueira Martins ${ }^{3}$ \\ Marco Aurélio Rodrigues de Souza ${ }^{4}$ \\ Willyan Caldeira Corte ${ }^{5}$ \\ Danilo Pereira Ribeiro 6
}

Resumo: Esse trabalho foi realizado com o objetivo de avaliar o desempenho das gramíneas Tifton-85, Paspalum vaginatum e Brachiaria mutica cultivadas em Sistemas Alagados Construídos (SACs) tratando efluente da suinocultura. Para isso, avaliou-se a produtividade de matéria fresca e matéria seca das gramíneas. O experimento foi composto por três SACs de fluxo subsuperficial preenchidos com brita zero, tendo, cada um, $10 \mathrm{~m}$ de comprimento, 1,0 m de largura e 0,25 m de profundidade. Cultivou-se uma espécie de gramínea por SAC. Durante o experimento foram coletadas amostras das gramíneas a cada 30 dias. As gramíneas Brachiaria mutica e Tifton 85 obtiveram as maiores produtividades médias de matéria seca, por corte, ambas com 2,6 tha-1. A Brachiaria mutica apresentou maior produtividade média de matéria fresca, acumulada nos 5 meses de cultivo, sendo 67,55 tha-1, o que evidencia seu potencial para cultivo em SACs na região Norte de Minas Gerais.

Palavras-chave: Suinocultura; Água residuária; Wetland.

\footnotetext{
${ }^{1}$ Engenharia Agrícola e Ambiental/ Instituto Federal do Norte de Minas Gerais - IFNMG Campus Januária, Brasil. E-mail: viktorpel@hotmail.com.

2 Engenharia Agrícola e Ambiental/ Instituto Federal do Norte de Minas Gerais - IFNMG Campus Januária, Brasil. E-mail: anapaula.colares@hotmail.com.

${ }^{3}$ Engenharia Agrícola e Ambiental/ Instituto Federal do Norte de Minas Gerais - IFNMG Campus Januária, Brasil. E-mail: rodrigonmartins@hotmail.com.

4 Engenharia Agrícola e Ambiental/ Instituto Federal do Norte de Minas Gerais - IFNMG Campus Januária, Brasil. E-mail: marcoaurelio.rdesouza@yahoo.com.br.

${ }^{5}$ Engenharia Agrícola e Ambiental/ Instituto Federal do Norte de Minas Gerais - IFNMG Campus Januária, Brasil. E-mail: willyancaldeira@ymail.com.

${ }^{6}$ DSC Engenharia Agrícola, Instituto Federal do Norte de Minas Gerais - IFNMG Campus Januária, Brasil. E-mail: danilo.ribeiro@ifnmg.edu.br.
} 